\title{
Whites' County-Level Racial Bias, COVID-19 Rates, and Racial Inequities in the United States
}

\author{
Marilyn D. Thomas ${ }^{1,2, *}$, Eli K. Michaels ${ }^{3}{ }^{(}$, Sean Darling-Hammond ${ }^{4}\left(\mathbb{D}\right.$, Thu T. Nguyen $^{5}{ }^{(D}$, \\ M. Maria Glymour ${ }^{1}$ and Eric Vittinghoff ${ }^{1}$ \\ 1 Department of Epidemiology and Biostatistics, School of Medicine, University of California, \\ 550 16th St 2nd floor, San Francisco, CA 94158, USA; Maria.Glymour@ucsf.edu (M.M.G.); \\ Eric.Vittinghoff@ucsf.edu (E.V.) \\ 2 Department of Psychiatry, School of Medicine, University of California, 1001 Potrero Ave, \\ San Francisco, CA 94110, USA \\ 3 Division of Epidemiology, School of Public Health, University of California, 2121 Berkeley Way, Room 5302, \\ Berkeley, CA 94720, USA; elikmichaels@berkeley.edu \\ 4 Goldman School of Public Policy, University of California, 2607 Hearst Ave, Berkeley, CA 94720, USA; \\ sean.darling.hammond@berkeley.edu \\ 5 Department of Family and Community Medicine, School of Medicine, University of California, \\ 995 Potrero Ave, San Francisco, CA 94110, USA; Thu.Nguyen@ucsf.edu \\ * Correspondence: Marilyn.Thomas@ucsf.edu
}

Received: 14 October 2020; Accepted: 17 November 2020; Published: 23 November 2020

\begin{abstract}
Mounting evidence reveals considerable racial inequities in coronavirus disease 2019 (COVID-19) outcomes in the United States (US). Area-level racial bias has been associated with multiple adverse health outcomes, but its association with COVID-19 is yet unexplored. Combining county-level data from Project Implicit on implicit and explicit anti-Black bias among non-Hispanic Whites, Johns Hopkins Coronavirus Resource Center, and The New York Times, we used adjusted linear regressions to estimate overall COVID-19 incidence and mortality rates through 01 July 2020, Black and White incidence rates through 28 May 2020, and Black-White incidence rate gaps on average area-level implicit and explicit racial bias. Across 2994 counties, the average COVID-19 mortality rate (standard deviation) was 1.7/10,000 people (3.3) and average cumulative COVID-19 incidence rate was 52.1/10,000 (77.2). Higher racial bias was associated with higher overall mortality rates (per 1 standard deviation higher implicit bias $b=0.65 / 10,000$ ( $95 \%$ confidence interval: $0.39,0.91$ ); explicit bias $b=0.49 / 10,000(0.27,0.70)$ ) and higher overall incidence (implicit bias $b=8.42 / 10,000$ $(4.64,12.20)$; explicit bias $\mathrm{b}=8.83 / 10,000(5.32,12.35))$. In 957 counties with race-specific data, higher racial bias predicted higher White and Black incidence rates, and larger Black-White incidence rate gaps. Anti-Black bias among Whites predicts worse COVID-19 outcomes and greater inequities. Area-level interventions may ameliorate health inequities.
\end{abstract}

Keywords: COVID-19; health inequities; racism and discrimination; social determinants of health

\section{Introduction}

Mounting evidence reveals considerable racial inequities in coronavirus disease 2019 (COVID-19) incidence and mortality rates in the United States (US) [1-6]. Structural racism-defined as ongoing interactions between macro-level systems, social forces, institutions, and ideologies that constrain the opportunities, resources, and power of minoritized racial groups-has been implicated as a fundamental cause of COVID-19 inequities [7,8]. Structural racism governs the distribution of a broad range of health-promoting resources that make it much more difficult for minoritized populations to access preventive care and avoid high-risk exposures [9-13]. For instance, residential segregation 
may increase the likelihood that racial/ethnic minoritized groups live in densely populated areas with substandard and crowded housing conditions $[1,14,15]$ that make social distancing practices more difficult. Thus, historical and ongoing structural racism likely drives the community spread of COVID-19 and the unequal burden of poor outcomes across racial/ethnic groups [1,5,16-18].

Area-level racial bias has been described as a "cognitive manifestation of structural racism" [19], which undergirds institutional and interpersonal forms of discrimination [20]. At the individual level, racial bias is defined as preconceived beliefs, attitudes, and expectations about members of a racial group [10], which can influence racial discrimination in day-to-day interactions and can manifest in social systems and institutions ranging from housing to healthcare [21]. Area-level racial bias is measured by aggregating racial bias data from multiple individuals to characterize the ambient social climate, in a geographically defined place, as it pertains to race and racism. Area-level bias may reflect norms and attitudes in a community or may represent a distinct community-level construct and has been shown to predict various domains of population health and health inequities $[19,22,23]$. For example, states with higher anti-Black bias spend less on disabled Medicaid enrollees [24], and various area-level measures of racial bias have been linked with overall rates of, and racial inequities in: adverse birth outcomes [25], police killings [26], cardiovascular risk factors [27], overall mortality [28], and mortality related to circulatory disease $[29,30]$. Proposed pathways linking area-level racial bias to health include institutional discrimination [29], disrupted social capital and community cohesion [28], and increased psychosocial stress [23], which can undermine health for both racially minoritized and White groups [27-30]. The relationship between area-level racial bias and COVID-19 outcomes have not, to our knowledge, been evaluated.

The purpose of this study is to estimate the relationship, at the US county level, between non-Hispanic (NH) White people's implicit and explicit anti-Black racial biases and a number of COVID-19 related outcomes: overall county-level incidence and mortality rates, incidence rates for Blacks and Whites, and gaps in incidence rates between Blacks and Whites. National mortality data disaggregated by race were not available at the time of this writing. We follow previous research $[29,30]$ and focus on county-level biases of Whites as the exposure of interest because COVID-19 outcomes are conceivably driven by racial bias within the most socially and economically advantaged group, due to its greater decision-making power and access to flexible resources. However, previous research has shown that county-level anti-Black bias among Whites predicts poor health outcomes for both Black and White populations [29], warranting close examination. Therefore, we hypothesized that higher anti-Black bias would predict higher overall COVID-19 mortality rates, higher incidence rates overall, among Blacks, and among Whites, and, assuming anti-Black bias more strongly impacts health outcomes for Blacks than Whites [25], larger Black-White incidence rate gaps.

\section{Materials and Methods}

\subsection{Exposure Assessment}

Exposure data were drawn from Project Implicit, a large, publicly available source of data on implicit and explicit biases about various social groups and topics [31]. Any person with an Internet connection can take a Project Implicit test at any time, and the results of each test are added to the publicly available dataset of test responses. Some workplaces and schools require participation [31].

Research suggests that previously established discriminatory policies, practices, and norms can create racial inequities in the private and public sectors that may worsen COVID-19 outcomes for Black residents in highly biased areas [7,9]. Thus, we downloaded data for all NH White Implicit Association Test (IAT) respondents of the Black-White race-related tests taken from 01 January 2017 to 31 December 2019 to capture the period preceding the COVID-19 pandemic but after President Trump was formally elected by the Electoral College (i.e., 19 December 2019) because the social climate related to discriminatory norms in the US may have shifted once he became the official President-elect [32]. 


\subsubsection{Implicit Racial Bias}

Implicit racial bias was assessed using the Implicit Association Test (IAT), which measures the speed of keyboard associations between images of Black vs. White faces and positive (e.g., "wonderful") vs. negative (e.g., "disgusting") words. Faster reaction time matching positive words with White faces and negative words with Black faces indicates cognitive dissonance between Black people and positive emotions. Using the standard scoring algorithm developed by Greenwald et al. [33], implicit bias scores range continuously from -2 to 2 , with negative values representing a pro-Black/anti-White bias, positive values representing an anti-Black/pro-White bias, and 0 representing a neutral score. IAT scores were $\mathrm{z}$-score transformed for analysis.

\subsubsection{Explicit Racial Bias}

Respondents were asked to rank their feelings of warmth/coldness toward Black people and White people on an 11-point Likert scale ranging from 0 "extremely cold" to 10 "extremely warm." Following previous work [22], we calculated the difference between the White and Black scores (continuous range -10 to 10). Negative values represent warmer feelings toward Black individuals (i.e., explicit pro-Black/anti-White bias), positive values represent warmer feelings toward White individuals (i.e., explicit anti-Black/pro-White bias), and 0 represent a neutral score. Explicit bias was z-score transformed for analysis.

\subsubsection{Exclusions}

There were $n=2,679,776$ implicit and explicit racial bias tests performed from 01 January 2017 to 31 December 2019. We restricted our sample to NH White individuals and excluded those residing outside of the US (territories were excluded). We also excluded those with missing county information to facilitate calculating county-level racial bias scores and merging with COVID-19 data. Following previous research [22,33], we excluded IAT tests where respondents made errors on greater than $30 \%$ of trials or had reaction times below 300 milliseconds on more than $10 \%$ of trials, thereby omitting bias scores with low accuracy and/or high response latencies. Our final sample size of US-based, NH White respondents with county information and complete and adequate implicit and explicit racial bias data was $n=723,271$ across 3017 counties. The characteristics of IAT respondents are presented in Appendix A.

\subsubsection{County-Level Averages}

We aggregated individual racial bias scores to the county level. The median number of Project Implicit responses per county was 28, ranging from 1 to 13,612 (mean (standard deviation) $=240(769)$ ). We used a population weighting function which substantially down-weights the relevance of low population counties, and these counties also tend to have fewer Project Implicit tests (Pearson correlation $=r(3142$ counties $)=0.77)$. Moreover, as we later describe, restricting our analysis to counties with 100 or more Project Implicit responses did not substantially change our results. We thus included as many counties as possible to strengthen power.

\subsection{Outcome Assessment}

Here, "incidence" denotes any ongoing or resolved case of COVID-19, and "mortality" indicates a COVID-19 case that resulted in death. Thus, the county-level per capita incidence rate is the cumulative proportion of all individuals in a given county who have contracted COVID-19 during the study period.

\subsubsection{Overall Incidence and Mortality Rates}

Overall incidence and death rates from 22 January 2020 to 01 July 2020 were calculated per 10,000 population using data reported by the widely cited Johns Hopkins University Coronavirus Resource Center, an online public-use database tracking daily counts across the US and worldwide [4]. 


\subsubsection{Race-Specific Incidence Rates}

Via litigation with the Centers for Disease Control and Prevention, The New York Times (NYT) secured race-disaggregated COVID-19 incidence counts through 28 May 2020 for $n=957$ counties [2]. Using these data, NYT calculated Black and White COVID-19 incidence rates per 10,000 population.

\subsubsection{Black-White Incidence Rate Gap}

We subtracted the White incidence rate from the Black incidence rate to calculate the difference in incidence rates between the two racial groups, with higher values representing more cases among Black compared to White people.

\subsection{Covariates}

Informed by theory and existing public health literature $[1,16,17,34]$, candidate covariates were selected a priori. Relevant confounders that measure county-level socioeconomic and demographic factors, and political ideology, include median age, percent with a bachelor's degree, percent Black, percent experiencing household crowding (more than 2 persons per room), population density (persons per-square-mile), and percent living below the federal poverty level. We also include percent voting for Donald Trump in the 2016 presidential election to proxy political and ideological factors affecting social distancing, mask compliance, and testing availability. County-level covariates were assessed using 5-year average estimates from the 2014-2018 American Community Survey (ACS) [35], which were extracted using the acs package in R [36]. Voter data were collected from Politico and accessed via GitHub [37]. Population density was measured using ACS population size divided by land area estimates in ArcGIS [38]. All covariates were assessed continuously. Model fitting details are described in Appendix B.

\subsection{Study Sample Selection}

Our sample in any given model consisted of all US counties for which there was available data for our measures of racial bias and COVID-19 outcomes. As explained above, disaggregated data were available for a smaller subset of counties. Thus, among 3142 US counties (including Washington DC), our samples ranged from 957 (31\%) to 2994 counties (95\%) depending on the outcome.

\subsection{Statistical Analysis}

Data were cleaned and prepared in R Studio Version 1.2.1335 (R Studio, Boston, MA, USA) and all statistical analysis was performed using STATA 16 (StataCorp LLC, College Station, TX, USA). We report the county-level distributions of NH White implicit and explicit racial biases, covariates, and COVID-19 outcomes. Having established that negative binomial and linear regression yielded similar results for the association between area-level racial bias and incidence and mortality in the overall population (Appendix C), we used multivariable linear regression with robust standard errors to estimate rates and rate differences for ease of interpretation. Following others [25,29,30], our models included counties for which we have data on all measures. We applied analytic weights (proportional to the inverse of the variance of the rate estimate in that county) to counties based on their population sizes to both ensure results are not driven by smaller counties (which are more plentiful), and to account for variation in the precision of our estimates of our exposure and outcome measures (which increases with county population). As described in Appendix B, our model fitting approach was data-driven [39]. Two sets of final models provide estimates of the relationship between each racial bias measure and outcome which are either (1) adjusted for covariates or (2) adjusted for the same set of covariates that were transformed to improve model fit. Detailed descriptions of these transformations are reported in Appendix B.

In all regression models, COVID-19 incidence and mortality rates are per 10,000 people. All regression coefficients (and 95\% confidence intervals (CI)) have been standardized such that 
they indicate the shift in a given rate outcome associated with a one standard deviation increase in the predictor (after adjustment for other covariates). This format allows comparability across racial bias measures. Only main associations are reported: final models adjusted for covariates are shown in Appendix D.

\subsection{Sensitivity Analyses}

As described in Appendix E, we performed the following sensitivity analyses: (1) restricting to first-time Project Implicit respondents since racial bias scores among repeated test-takers may regress toward the mean [40], (2) constructing our exposures by aggregating across Whites who specifically identified as non-Hispanic (rather than across Whites who did not identify as Hispanic), (3) restricting to counties with at least 20 (and then again with at least 100) Project Implicit respondents to avoid unstable estimates [25], and (4) restricting all analyses to the 957 counties for which we have NYT race-specific data.

\section{Results}

\subsection{Sample Characteristics}

Table 1 shows the distribution of county-level NH White racial bias scores, COVID-19 rates, and covariate values. Across 2994 counties, NH Whites' implicit and explicit (hereafter implicit and explicit) racial bias had mean (standard deviation (SD)) scores of $0.38(0.14)$ and $0.40(0.62)$, respectively. These were very similar to average bias levels in the 957-county set $(0.38(0.14)$ and $0.40(0.38)$ ). Incidence and mortality rates are reported per 10,000 people. Across 2994 counties, the average COVID-19 mortality rate was 1.72 per 10,000 (3.33) and incidence rate was 52.1 per 10,000 (77.2) for the overall population. Across the 957-county set, these rates were 3.15 (4.42) and 82.05 (86.57). Average confounder values for the two county sets were generally similar, with the exception of population density and percent Black, which were higher in the smaller subset of counties. Across the 957 counties, the average incidence rate among Whites (16.5 (27.5)) was lower than among Blacks (35.6 (92.5)), for an average Black-White gap in incidence rate of 19.1 (78.8).

Table 1. US county-level distribution of racial bias, COVID-19 incidence and mortality rates, and socioeconomic, demographic, and political variables for the samples of 2994 counties (in models assessing overall rates using Johns Hopkins data) and 957 counties (in models assessing race-disaggregated rates using The New York Times (NYT) data).

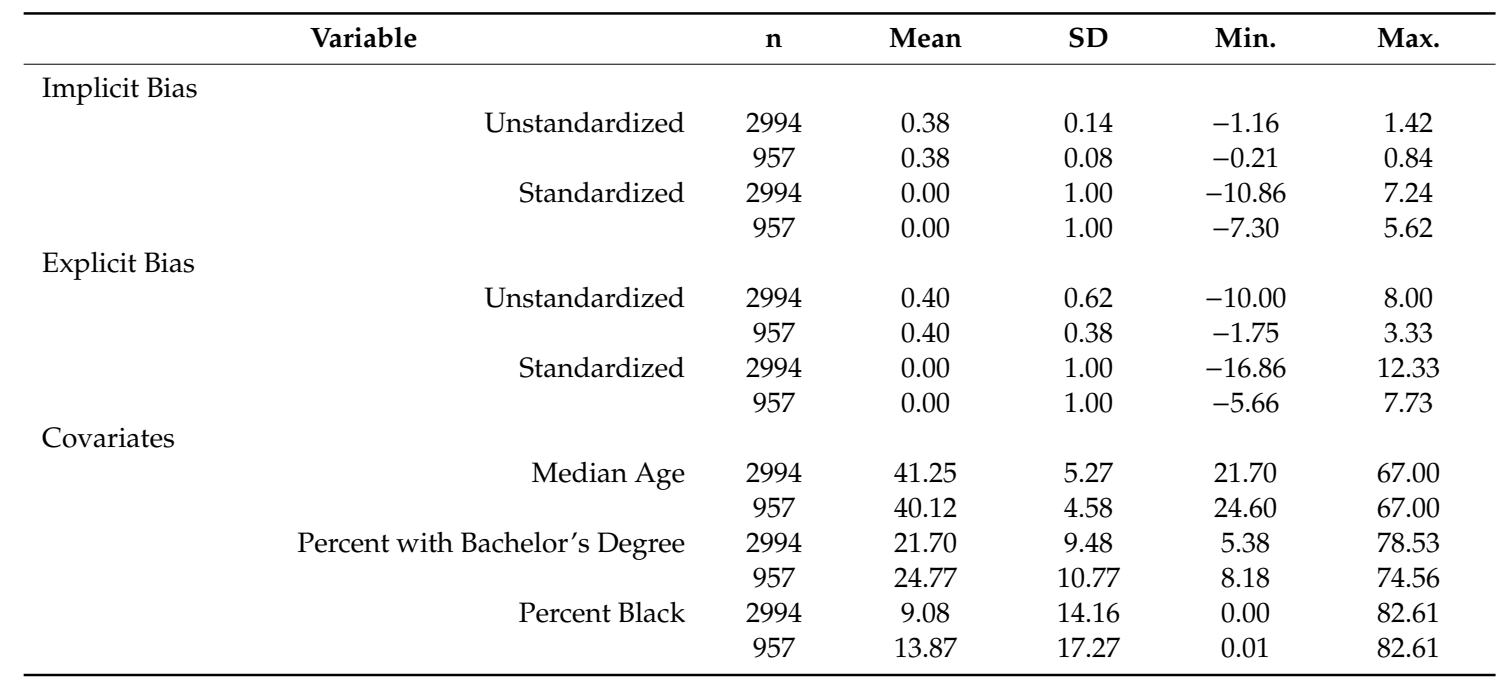


Table 1. Cont.

\begin{tabular}{|c|c|c|c|c|c|}
\hline Variable & $\mathbf{n}$ & Mean & SD & Min. & Max. \\
\hline Percent in Poverty & 2994 & 15.50 & 6.19 & 2.30 & 55.10 \\
\hline & 957 & 15.23 & 6.13 & 3.46 & 41.75 \\
\hline \multirow[t]{2}{*}{ Percent in Crowded Housing } & 2994 & 2.30 & 1.74 & 0.00 & 15.46 \\
\hline & 957 & 2.22 & 1.47 & 0.00 & 13.06 \\
\hline \multirow[t]{2}{*}{ Percent Voting Trump (2016) } & 2994 & 63.55 & 15.21 & 4.12 & 91.86 \\
\hline & 957 & 56.30 & 14.46 & 9.59 & 89.96 \\
\hline \multirow[t]{2}{*}{ Population Density } & 2994 & 283.03 & 1834.28 & 0.24 & $71,509.98$ \\
\hline & 957 & 540.64 & 3055.53 & 1.95 & $71,509.98$ \\
\hline \multirow[t]{2}{*}{ Population Size } & 2994 & 111,296 & 371,533 & 463 & $10,000,000$ \\
\hline & 957 & 195,433 & 448,658 & 3838 & $8,336,817$ \\
\hline \multicolumn{6}{|l|}{ Mortality Rate (per 10,000) } \\
\hline \multirow[t]{2}{*}{ Overall Mortality Rate, $7 / 1 / 20$} & 2994 & 1.72 & 3.33 & 0.00 & 37.84 \\
\hline & 957 & 3.15 & 4.42 & 0.00 & 37.84 \\
\hline \multicolumn{6}{|l|}{ Incidence Rate (per 10,000) } \\
\hline \multirow[t]{2}{*}{ Overall Incidence Rate, $7 / 1 / 20$} & 2994 & 52.12 & 77.21 & 0.00 & 1319.57 \\
\hline & 957 & 82.05 & 86.57 & 0.00 & 864.93 \\
\hline White Incidence Rate, 5/28/20 & 957 & 16.48 & 27.51 & 0.00 & 455.00 \\
\hline Black Incidence Rate, 5/28/20 & 957 & 35.59 & 92.45 & 0.00 & 1181.00 \\
\hline Black-White Incidence Rate Gap, 5/28/20 & 957 & 19.11 & 78.80 & -204.00 & 1069.00 \\
\hline
\end{tabular}

SD = standard deviation. While there were 3142 counties for which we had data on any given variable, our adjusted models had either 2994 counties (for overall rate models) or 957 counties (for race-disaggregated rate models) as these were the counties which had information on all model-relevant variables. Above, we report averages for the 2994 and 957 county sets to demonstrate similarities and differences between county sets. Unstandardized exposure summary statistics provide a sense of aggregate racial bias central tendency, which trend slightly above 0 (indicating general pro-White bias). Standardized exposure measures provide ease of comparability against regression coefficients, which are $\mathrm{x}$-standardized and reported later.

\subsection{Multivariable Regression}

In models adjusted for covariates, a standard deviation higher average implicit bias was associated with: a higher overall COVID-19 incidence rate $(b=12.11(6.96,17.25))$, higher overall COVID-19 mortality rate $(b=0.9(0.54,1.25))$, higher incidence rate among Whites $(b=4.20(1.65,6.75))$, higher incidence rate among Blacks $(b=10.25(5.00,15.51))$, and larger Black-White incidence rate gap $(b=6.05(2.61,9.50))$.

Higher average explicit bias was also associated with worse COVID-19 outcomes in adjusted models: a higher COVID-19 incidence rate $(b=11.24(6.35,16.13))$, higher overall mortality rate $(b=0.65(0.32,0.98))$, higher incidence rate among Whites $(b=4.27(1.56,6.98))$, higher incidence rate among Blacks $(b=13.1(8.45,17.75))$, and larger Black-White incidence rate gap $(b=8.83(5.42,12.24))$.

The above pattern of findings largely holds in more flexible models incorporating confounder controls, variable transformations, and interactions, with one exception: after adjusting for transformed and interacted confounders, $95 \%$ confidence intervals for implicit bias as a predictor of the Black-White incidence rate gap encompass the null. All regression estimates are presented in Table 2.

Table 2. Associations of implicit and explicit racial bias with COVID-19 rates per 10,000 individuals in the county using standardized coefficients: adjusted for confounders (Adjusted) or adjusted for confounders with relevant transformations and interactions (Adjusted and Transformed).

\begin{tabular}{|c|c|c|c|c|c|c|}
\hline \multicolumn{2}{|c|}{ Anti-Black Racial Bias } & $\begin{array}{l}\text { Overall } \\
\text { Mortality Rate } \\
(95 \% \text { CI })\end{array}$ & $\begin{array}{l}\text { Overall } \\
\text { Incidence Rate } \\
(95 \% \text { CI })\end{array}$ & $\begin{array}{l}\text { White } \\
\text { Incidence Rate } \\
(95 \% \text { CI })\end{array}$ & $\begin{array}{l}\text { Black } \\
\text { Incidence Rate } \\
(95 \% \text { CI) }\end{array}$ & $\begin{array}{l}\text { Black-White } \\
\text { Incidence Rate Gap } \\
(95 \% \text { CI) }\end{array}$ \\
\hline \multirow{6}{*}{ Implicit Bias } & $\mathrm{N}$ & $\begin{array}{l}\text { A: } 2,994 / \\
\text { AT: } 2,933\end{array}$ & $\begin{array}{l}\text { A: } 2,994 / \\
\text { AT: } 2,933\end{array}$ & 957 & 957 & 957 \\
\hline & Adjusted & $\begin{array}{l}0.9^{* * *} \\
(0.54,1.25)\end{array}$ & $\begin{array}{l}12.11^{* * *} \\
(6.96,17.25)\end{array}$ & $\begin{array}{l}4.20^{* *} \\
(1.65,6.75)\end{array}$ & $\begin{array}{l}10.25 * * * \\
(5.00,15.51)\end{array}$ & $\begin{array}{l}6.05^{* *} \\
(2.61,9.50)\end{array}$ \\
\hline & $R^{2}$ & 0.50 & 0.24 & 0.54 & 0.30 & 0.17 \\
\hline & Adjusted and & $0.65^{* * *}$ & $8.42 * * *$ & $4.89 * * *$ & $7.54^{* *}$ & 2.65 \\
\hline & Transformed & $(0.39,0.91)$ & $(4.64,12.20)$ & $(2.19,7.59)$ & $(2.10,12.97)$ & $(-0.93,6.23)$ \\
\hline & $R^{2}$ & 0.60 & 0.38 & 0.62 & 0.32 & 0.18 \\
\hline
\end{tabular}


Table 2. Cont.

\begin{tabular}{|c|c|c|c|c|c|c|}
\hline \multicolumn{2}{|c|}{ Anti-Black Racial Bias } & \multirow{2}{*}{$\begin{array}{l}\begin{array}{l}\text { Overall } \\
\text { Mortality Rate } \\
(95 \% \text { CI) }\end{array} \\
0.65^{* * *} \\
(0.32,0.98)\end{array}$} & \multirow{2}{*}{$\begin{array}{l}\begin{array}{l}\text { Overall } \\
\text { Incidence Rate } \\
\text { (95\% CI) }\end{array} \\
11.24^{* * *} \\
(6.35,16.13)\end{array}$} & \multirow{2}{*}{$\begin{array}{l}\text { White } \\
\text { Incidence Rate } \\
(95 \% \text { CI) }\end{array}$} & \multirow{2}{*}{$\begin{array}{l}\text { Black } \\
\text { Incidence Rate } \\
(95 \% \text { CI })\end{array}$} & \multirow{2}{*}{$\begin{array}{l}\text { Black-White } \\
\text { Incidence Rate Gap } \\
\text { (95\% CI) }\end{array}$} \\
\hline Explicit Bias & Adjusted & & & & & \\
\hline & $R^{2}$ & 0.49 & 0.24 & 0.54 & 0.31 & 0.17 \\
\hline & Adjusted and & $0.49^{* * *}$ & $8.83^{* * *}$ & $4.18^{* *}$ & $10.29 * * *$ & $6.11^{* *}$ \\
\hline & Transformed & $(0.27,0.70)$ & $(5.32,12.35)$ & $(1.75,6.61)$ & $(5.43,15.15)$ & $(2.68,9.54)$ \\
\hline & $R^{2}$ & 0.59 & 0.38 & 0.62 & 0.32 & 0.19 \\
\hline
\end{tabular}

$\mathrm{CI}=$ confidence interval. Models estimate COVID-19 outcome rates per 10,000 individuals (and associated 95\% confidence intervals). Models involving implicit and explicit bias were run separately, totaling 20 models. Coefficients are standardized on $x$ such that each indicates the shift in $y$ (unstandardized) associated with a one standard deviation increase in x. "Adjusted" (A) models are adjusted for median age, percent with bachelor's degree, percent Black, percent in poverty, percent in crowded housing, population density, and percent voting Trump. "Adjusted and Transformed" (AT) models are adjusted for median age, percent with bachelor's degree, percent with a bachelor's degree-squared, the log of percent Black, percent in poverty, percent in crowded housing, population density, percent voting Trump, percent experiencing crowding $X$ population density, percent with a bachelor's degree X the log of percent Black, percent with a bachelor's degree squared X the log of percent Black, and median age $X$ percent voting for Trump. AT models on overall mortality and incidence rates are based on $\mathrm{n}=2933$ counties as 61 counties from the larger set of 2994 counties had percentage Black values equal to 0 , thus the natural log could not be defined in those cases, resulting in the omission of these counties. Inclusion, with imputed, extremely low values for percent Black 0.007 (the lowest non-zero value occurring in our data), did not change results. To avoid imputation, we present results based on the 2933 counties for which log values could be calculated. ${ }^{* *} p<0.01,{ }^{* * *} p<0.001$

\subsection{Sensitivity Analyses}

Models performed similarly to our main models when we restricted to first-time Project Implicit test-takers, to counties with at least 20 Project Implicit tests, to counties with at least 100 tests, and to the 957 counties in the NYT data, and when we limited our Project Implicit sample to White individuals who explicitly identified as non-Hispanic (rather than to those who did not identify as Hispanic). The notable exception was that after restricting our analysis to counties with at least 100 Project Implicit tests, implicit bias became a statistically significant predictor of the Black-White COVID incidence rate gap in models adjusting for transformed and interacted confounders.

\section{Discussion}

Our ecologic study is the first to report associations of county-level NH Whites' implicit and explicit racial bias with COVID-19 incidence and mortality rates in the United States. This finding aligns with previous evidence linking area-level racial bias with rates of disease and mortality, and is among the first to explore this relationship with an infectious rather than chronic disease. [25,29]. We found that county-level average racial bias among NH Whites was positively associated with COVID-19 incidence rates among both Black and White residents, consistent with prior work suggesting that area-level racial bias may be harmful for everyone's health [28,29,41]. Finally, higher levels of explicit (but not implicit) anti-Black bias were associated with greater Black-White gaps in COVID-19 incidence rates after accounting for other predictors. This finding is consistent with prior work showing area-level explicit racial bias to be a stronger predictor of racial inequities in health outcomes when compared with implicit bias $[25,29]$. Below, we posit several potential pathways linking county-level racial bias of NH Whites with COVID-19 incidence, mortality, and inequities to guide future research and inform targeted interventions.

Whites' anti-Black racial bias may flow through political and social inequalities that can lead to Black-White inequities in COVID-19 incidence and disease severity. For instance, racially biased decision making by private and public sector arbiters in high bias counties may result in disparate opportunities for members of different racial groups. Research has found, for example, that Whites' racial bias is linked to Black-White income inequality [42]. Biased decision making could also contribute to racial inequities in COVID-19 outcomes through differences in access to protective resources such as private versus public transportation options, physical distancing versus crowding within various 
spaces (e.g., homes, neighborhoods, workplaces), access to quality healthcare, and other structural factors. In addition, Black people are over-represented among lower wage workers deemed as "essential" in the workforce (e.g., caregivers, bus drivers, cashiers), and thereby maintain higher risk of COVID-19 exposure compared to White people who are more likely to be able to work from home $[43,44]$. Further, ongoing inequities such as residential segregation and differential access to quality housing, healthcare, higher education, and higher wages have long contributed to Black-White inequities in a range of illnesses including cardiovascular disease and risk of mortality [29,30,45], all of which are associated with increased risk of COVID-19 infection and worse disease severity [46]. Finally, in counties with higher NH White racial bias, Black people report decreased access to healthcare services [29]. Future work may consider evaluating whether structural inequities, such as income inequality and healthcare access, partially mediate the association between area-level racial bias and racial inequities in COVID-19 incidence and mortality.

Community-level social capital—defined as an arrangement of resources that are accessed by community members [47] —is another plausible mechanism linking racial bias with county-level COVID-19 incidence and mortality. A recent study showed that counties with higher social capital operating as civic norms that foster cooperation, collective action, and community trust had increased social distancing [48]. Community-level social capital has also been shown to mediate associations between community-level racial prejudice and mortality among Black and White residents [28], which may help explain, in part, our finding of higher incidence among Whites. Indicators of social capital include interpersonal trust, civic and political engagement, and access to services and resources [47]. For example, socially cohesive communities are more successful at collective lobbying to preserve local services and amenities [49,50], benefiting members of advantaged and disadvantaged racial groups. It is conceivable that residents living in counties with higher anti-Black bias are less trusting of community members, leading to the erosion of social capital, which is harmful for both Black and White residents. Support for shared resources and programs that benefit the population as a whole may be especially important in a pandemic for the poor, homeless, institutionalized elderly, and other low-status groups in biased areas, regardless of race. Lower social capital could also disrupt trust and reciprocity between community members, possibly reducing the motivation to practice collective action to protect each other from COVID-19 by wearing a mask, physical distancing, or sharing resources and information. Social capital may be improved by public policies aimed to reduce racial residential, educational, and occupational segregation, thereby fostering meaningful intergroup contact, which has been shown to reduce prejudice and improve in-group connections, cross-group empathy, and community trust [51-53]. Examining changes in social capital as a moderator or mediator of the association between county-level racial bias and COVID-19 outcomes is an important area for future research [28].

A final plausible mechanism linking county-level racial bias with COVID-19 outcomes and inequities is greater overall exposure to psychosocial stress. Counties where NH White individuals harbor greater levels of anti-Black racial bias may be characterized by greater racial tension and hostility, leading to stressful interracial interactions which can trigger biopsychosocial stress-response processes [54,55]. These processes, in turn, may decrease immunity [56], increase generalized susceptibility [57] to infectious agents [6], and lead to physical and mental exhaustion which impairs adherence to health-preserving behavioral changes, such as mask-wearing. While community tension and hostility may create stress for everyone, the effects may be disproportionately harmful for Black residents. For example, some have suggested that Black individuals living in areas with higher levels of racial bias may encounter more interpersonal and institutional racial discrimination [23,25], a toxic psychosocial stressor associated with myriad adverse health outcomes [20]. They may also be more likely to experience uniquely stressful life events (such as racism-related job losses or police encounters) [54]. Moreover, living in counties with higher levels of anti-Black bias may cause stress from collective or vicarious racism experiences, even in the absence of direct interpersonal racism encounters [54]. Finally, chronic contextual stress (stress resulting from the socio-political climate and inequitable social 
structure) [54] may be more salient in counties with more racial bias. Indeed, previous work has linked community-level racial bias with stress-related outcomes among racially minoritized groups, including cardiovascular risk factors and adverse birth outcomes $[25,27,29]$. Future research should examine these potential mediating pathways linking area-level bias to COVID-19 and other adverse health outcomes.

There are important methodological considerations. This cross-sectional, ecologic study leveraged several large, publicly available national datasets. The design was not intended to establish causality, but rather to determine whether, for whom, and to what extent, county-level racial bias is associated with COVID-19 outcomes. We utilize Project Implicit data to ascertain racial bias in part because implicit bias data do not rely on self-report, thereby circumventing the self-censorship inherent in many measures of racial attitudes. Importantly, county-level racial bias scores are only representative of those who chose to take the IAT, which limits generalizability. However, previous work showed high construct validity of county-level IAT scores in comparison to several nationally representative sources of data on racial attitudes [22].

Temporal factors and data limitations present a threat to external validity. Outcome data are comprised of county-level cases and deaths that occurred relatively early in the pandemic, during which time outbreaks were clustered in locations with high population densities (e.g., New York City, nursing homes, meatpacking plants) and may not be generalizable to more rural or sparsely populated areas. Further, race-disaggregated data excludes the surge of COVID-19 cases in the Sun Belt during the summer and in the Midwest during the fall; hence, counties in the Northeast are likely overrepresented. Future research with more national data and a longer time frame will bolster our understanding of these associations and whether they change over the course of the pandemic. Critically, disaggregated data on morality rates were not available, and disaggregated data on incidence rates were only available for 957 counties. As noted in Table 1, the 957 counties with race-disaggregated data had higher overall COVID-19 incidence and mortality rates, higher percentages of Black individuals, higher populations, and higher population densities compared to counties for which race-disaggregated data were not available. Additionally, the disaggregated cases occurred around a time when $83 \%$ of the population resided in US counties with high COVID-19 prevalence [58]. Given the characteristics of these 957 counties, our disaggregated results may be most appropriately generalized to more populous and diverse counties.

As noted, our goal was to evaluate the association between racial bias and COVID-19 outcomes. Internal validity in this regard is strengthened by our theory- and data-driven approaches to address confounding. Still, unmeasured confounding certainly remains. For example, we adjust for percent voting for Trump in 2016 in part to proxy political and ideological factors that may contribute COVID-19 spread and detection. However, this indicator is imperfect and there likely remains confounding via unmeasured socio-political pathways through which $\mathrm{NH}$ whites' county-level racial bias may influence COVID-19 outcomes. In addition, variation in $R^{2}$ values suggests that some variables in our collective set of covariates predict more of the variance than others. For instance, our variable set predicts more variance in overall mortality than in overall incidence. This suggests that some variables that are not included in the model are particularly important predictors of incidence but less so for predicting mortality.

\section{Conclusions}

Greater county-level anti-Black bias among non-Hispanic Whites is associated with higher overall COVID-19 mortality and incidence rates, higher incidence rates for Whites and Blacks, and higher White-Black incidence rate gaps after accounting for other county-level predictors. Racial bias helps explain not only where COVID-19 is most negatively impacting individuals of all races, but also where the disease is disproportionately impacting Black individuals. This has critical implications for future research and present policy. Future studies should examine mediators and modifiers of the association between anti-Black bias and COVID-19 outcomes, especially mechanisms amenable 
to short-term policy responses. Public policies promoting meaningful community-level intergroup contact may help mitigate the effects of racial bias through increased cross-group trust and empathy, and social capital. Given the incomplete nature of available data on this critical issue, researchers and policymakers should prioritize the development of a national registry of COVID-19 patients including demographic characteristics. Finally, while there are certainly many direct steps counties should consider to drive-down COVID-19 inequities, reducing area-level racial bias may be essential to ensuring successful efforts.

Author Contributions: M.D.T., primary investigator, conceptualized the study, coordinated all logistics related to data collection, cleaning and coding, designed and performed statistical analyses (and takes responsibility for the integrity of the data analyzed), and took final responsibility for drafting the manuscript; E.K.M. assisted study conceptualization, study design, performed data collection, cleaning and coding, assisted in statistical analyses and interpretation, and editing and approval of the manuscript; S.D.-H. assisted in study design, performed data collection, cleaning and coding, statistical analyses and interpretation, and editing and approval of the manuscript; T.T.N. assisted in data analysis and interpretation, and editing and approval of the manuscript; M.M.G. assisted in study design, data analysis and interpretation, and editing and approval of the manuscript; E.V. assisted in statistical analyses and interpretation, and editing and approval of the manuscript. This manuscript has not been previously published, either in whole or in part, nor have the findings been posted online, and is solely submitted to the International Journal of Environmental Research and Public Health. All authors have read and agreed to the published version of the manuscript.

Funding: MD Thomas was supported by an award made from NIGMS grant UL1GM118985. EK Michaels was supported by an award made from NHLBI grant F31HL151284. TT Nguyen was supported by an award made from NIMHD grant R00MD012615. The sponsors had no role in the design, execution, interpretation, or writing of the study.

Acknowledgments: We wish to thank the reporters at The New York Times for sharing the race-specific data that they sued to collect from the Center for Disease Control and Prevention. We would also like to thank Rucker Johnson for comments on statistical analyses.

Conflicts of Interest: The authors declare no conflict of interest.

\section{Appendix A. Characteristics of IAT Respondents Used to Construct County-Level Racial Bias Scores}

Table A1. Characteristics of IAT test-takers aggregated to create county average IAT scores, 2017-2019 $(\mathrm{n}=723,256)$.

\begin{tabular}{|c|c|}
\hline Characteristic & n $(\%)$ \\
\hline \multicolumn{2}{|l|}{ Gender identity } \\
\hline Woman & $451,908(62.5)$ \\
\hline Man & $262,992(36.4)$ \\
\hline Nonbinary & $7939(1.1)$ \\
\hline NA & $417(0.1)$ \\
\hline Age (mean (SD)) & $29.7(13.9)$ \\
\hline \multicolumn{2}{|l|}{ Educational attainment } \\
\hline$<$ high school & $97,418(13.5)$ \\
\hline high school graduate & $283,493(39.2)$ \\
\hline bachelor's degree & $340,940(47.1)$ \\
\hline Missing & $1405(0.2)$ \\
\hline \multicolumn{2}{|l|}{ Number previous tests } \\
\hline$x^{1}$ & $477,404(66.0)$ \\
\hline 1 & $143,625(19.9)$ \\
\hline 2 & $52,608(7.3)$ \\
\hline $3-5$ & $39,000(5.4)$ \\
\hline $6+$ & $9861(1.4)$ \\
\hline Missing & $758(0.1)$ \\
\hline Implicit racial bias (mean (SD)) & $0.36(0.41)$ \\
\hline Explicit racial bias (mean (SD)) & $0.24(1.54)$ \\
\hline
\end{tabular}

Project Implicit sample restricted to NHW, US-based respondents with complete and adequate test data and county data. 


\section{Appendix B. Confounder Selection and Transformations}

\section{Appendix B.1. Confounder Selection}

As mentioned in our manuscript, candidate confounders were chosen a priori and included county-level median age, percent with a bachelor's degree, percent Black, percent experiencing household crowding, population density, percent living below the federal poverty level, percent of voting for Donald Trump in the 2016 presidential election, and the Index of Concentration at the Extremes (ICE) - a measure of racialized economic segregation (high-income White households minus low-income Black households, ranging from -1 to 1) [59]. Covariates are coded and assessed continuously.

Model specifications were evaluated using data-driven approaches [39]. Possible confounders were assessed using several regressions: (1) direct covariate-outcome associations and (2) main exposure-outcome association adjusted for one covariate at a time. Pearson correlations were estimated among all covariates. Principal components analysis evaluated which covariates explained most of the variance-covariance within the data structure. Multicollinearity between covariates was assessed using variance inflation factors (VIF). Final models were appraised for best fit using nested modeling and Akaike and Bayesian information criteria (AIC and BIC).

Median age, percent bachelor's degree, percent Black, population density, and percent voting for Trump were directly associated with COVID-19 incidence and confounded main exposure-outcome association when adjusted for one single covariate at a time $(p<0.05)$. The same was found for COVID-19 death rates with the exception of implicit bias adjusted for median age. Strong inverse correlations were found for ICE with percent Black $(r=-0.74)$ and percent persons in poverty $(r=-0.76)$. Almost $100 \%$ of the first principal component explained the variance-covariance, with the strongest contributors being percent poverty, percent Black, and ICE (|0.46-0.55|). We ultimately omitted ICE, but retained percent Black and percent poverty, from future model-building evaluations for two reasons. First, ICE is comprised of percent Black and percent poverty. Secondly, ICE was not directly associated with COVID-19 incidence or death rates. No multicollinearity was detected in regression models including all remaining covariates (VIF $<4$ ).

Nested model building favored the inclusion median age, percent bachelor's degree, percent Black, population density, and percent voting for Trump. AIC and BIC values showed that the best fit models included the same covariates favored in the nested models, in addition to percent poverty and percent crowding. Because AIC and BIC values suggest that including percent poverty and percent crowding improve model fit, and because poverty and household crowding are strong predictors of COVID-19 deaths [1], percent poverty and percent crowding were included in our analysis. Hence, our final models were adjusted for median age, percent bachelor's degree, percent Black population, persons in poverty, percent household crowding, percent population density, and percent voting for Trump in 2016.

\section{Appendix B.2. Confounder Transformations and Interactions}

As noted in the body of the manuscript, we attempted to obtain a less biased estimate of the relationship between our bias measures and COVID-19 outcome measures by adjusting for seven covariates: median age, percent with a bachelor's degree, percent Black, percent in poverty, percent experiencing crowding (meaning more than two per room), population density, and percent who voted for President Trump in 2016.

The use of linear regression to estimate the relationship between any two variables assumes linear relationships between all predictors and outcome and the inclusion of relevant interaction terms. To reduce bias in our estimate of the relationship between bias and outcomes, we thus sought to discern which, if any, confounders to transform and to interact with one another. We first reviewed the shape of the relationship between each confounder and each outcome using locally weighted regressions via the "loess" command in STATA 16. We then created appropriate transformed versions of each 
confounder which exhibited a non-linear relationship with our outcomes (creating square terms for parabolic relationship, creating log terms for diminishing return shaped relationships, etc.). Next, we employed likelihood ratio tests to determine which of transformations performed better than their untransformed analogues, and discerned that log percent Black and percent with a Bachelor degree with a square term performed better than their analogues, with $\chi^{2}$ likelihood ratio values of 874.14 $(p<0.0001)$ and $49.89(p<0.0001)$ respectively, on their ability to predict the overall COVID-19 rate.

We next discerned which, if any, $1 \times 1$ interactions to include in our models. We vetted each potential interaction, then included the set of three $1 \times 1$ interactions which did the most to improve our model fit. These were interaction terms on percent experiencing crowding with population density, percent with a bachelor's degree (and its square term) with the log of percent Black, and median age with percent voting for Trump in 2016.

Including these additional terms improved model fit from an average $\mathrm{R}^{2}$ value in adjusted models of 0.36 to an average $R^{2}$ value in adjusted and transformed models of 0.43 , and markedly improved the fit in some models by a factor of as much as 1.6.

Table A2. $R^{2}$ values in adjusted versus adjusted and transformed models.

\begin{tabular}{llcc}
\hline Predictor & Outcome & Adjusted Models & Adjusted and Transformed Models \\
\hline \multirow{4}{*}{ Implicit bias } & Overall incidence rate & 0.24 & 0.38 \\
& White incidence rate & 0.54 & 0.62 \\
& Black incidence rate & 0.30 & 0.32 \\
& Black-White rate gap & 0.17 & 0.18 \\
& Overall mortality rate & 0.50 & 0.60 \\
& Overall incidence rate & 0.23 & 0.38 \\
Explicit Bias & White incidence rate & 0.54 & 0.62 \\
& Black incidence rate & 0.50 & 0.60 \\
& Black-White rate gap & 0.17 & 0.19 \\
Average & Overall mortality rate & 0.49 & 0.59 \\
& & 0.36 & 0.43 \\
\hline
\end{tabular}

\section{Appendix C. Negative Binomial Regression Results}

Table A3. Comparing linear regression and negative binomial regression models: COVID-19 incidence and mortality rates associated with a one unit increase in county-level implicit and explicit bias (adjusted for other predictors), per 10,000 individuals in the county $(n=2994)$.

\begin{tabular}{lllll}
\hline & \multicolumn{2}{l}{ Incidence Rate } & \multicolumn{2}{l}{ Mortality Rate } \\
\hline & Linear & Negative Binomial & Linear & Negative Binomial \\
\hline \multirow{2}{*}{ Implicit Bias } & $215.5^{* * *}$ & $213.6^{* * *}$ & $16.0^{* * *}$ & $18.9^{* * *}$ \\
$R^{2}$ & $(123.9,307.1)$ & $\left(144.1^{\mathrm{f}}, 283.0\right)$ & $(9.6,22.3)$ & $(11.6,26.3)$ \\
Explicit Bias & 0.24 & $0.01^{\mathrm{f}}$ & 0.50 & $0.03^{\mathrm{f}}$ \\
$R^{2}$ & $44.2^{* * *}$ & $51.7^{* * *}$ & $2.6^{* * *}$ & $4.1^{* * *}$ \\
& $(24.9,63.4)$ & $(33.4,70.1)$ & $(1.3,3.8)$ & $(2.1,6.2)$ \\
\hline
\end{tabular}

Models estimate COVID-19 outcome rates per 10,000 individuals (and associated 95\% confidence intervals).

${ }^{\mathrm{I}}$ Pseudo $\mathrm{R}^{2}$. ${ }^{* * *} p<0.001$ 


\section{Appendix D. Regression Model Results}

Table A4. Predicted shift in COVID-19 rates associated with a one standard deviation increase in county-level implicit bias (adjusted for other predictors), per 10,000 individuals in the county.

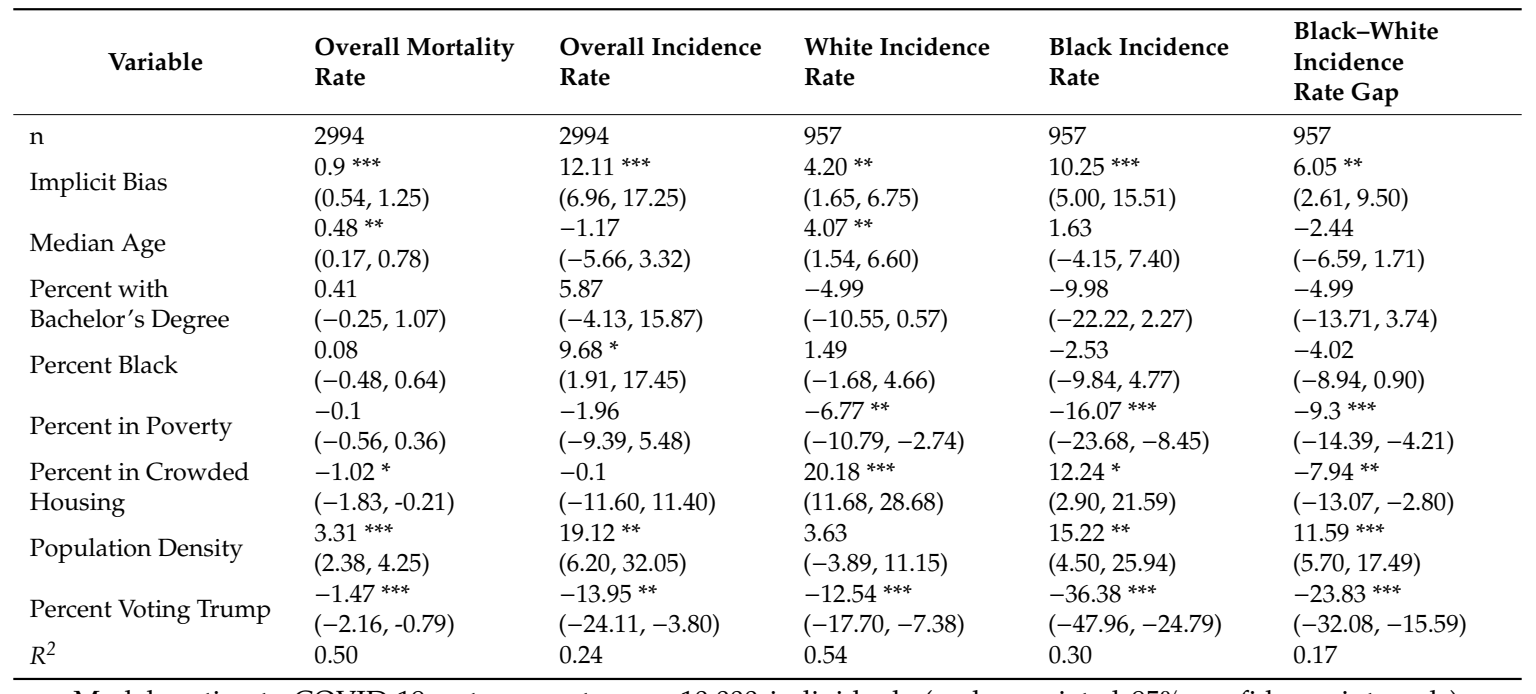

Models estimate COVID-19 outcome rates per 10,000 individuals (and associated 95\% confidence intervals). Coefficients are standardized on $\mathrm{x}$ such that each indicates the shift in $\mathrm{y}$ (unstandardized) associated with a one standard deviation increase in $\mathrm{x} .{ }^{*} p<0.05,{ }^{* *} p<0.01,{ }^{* * *} p<0.001$

Table A5. Predicted shift in COVID-19 rates associated with a one standard deviation increase in explicit bias (adjusted for other predictors), per 10,000 individuals in the county.

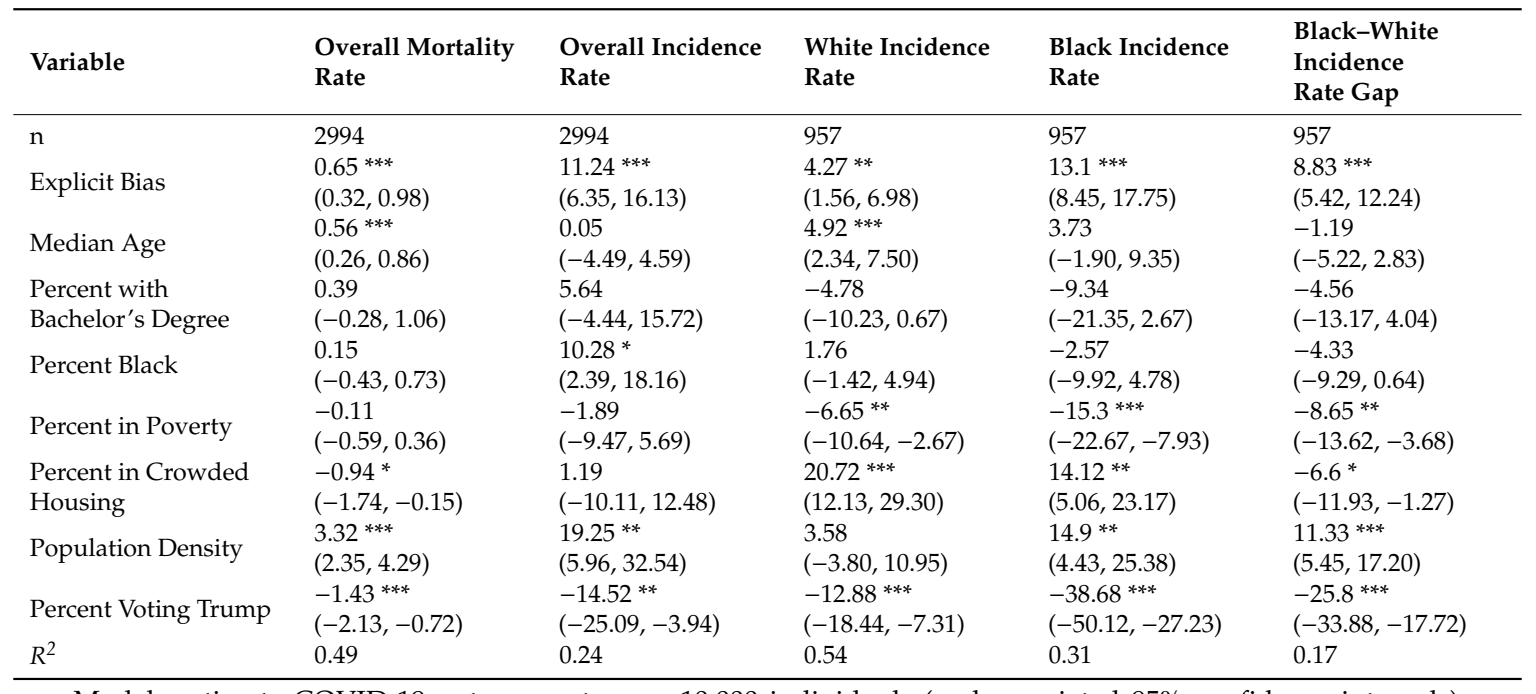

Models estimate COVID-19 outcome rates per 10,000 individuals (and associated 95\% confidence intervals). Coefficients are standardized on $x$ such that each indicates the shift in $y$ (unstandardized) associated with a one standard deviation increase in $\mathrm{x} .{ }^{*} p<0.05,{ }^{* *} p<0.01,{ }^{* * *} p<0.001$ 


\section{Appendix E. Sensitivity Results}

Appendix E.1. Complete Sensitivity Analysis

Table A6. Complete sensitivity analyses.

\begin{tabular}{|c|c|c|c|c|c|}
\hline \multirow{2}{*}{ Outcome } & \multirow{2}{*}{ Model Type } & \multicolumn{2}{|c|}{ Implicit Bias } & \multicolumn{2}{|c|}{ Explicit Bias } \\
\hline & & Adjusted & $\begin{array}{l}\text { Adjusted and } \\
\text { Transformed }\end{array}$ & Adjusted & $\begin{array}{l}\text { Adjusted and } \\
\text { Transformed }\end{array}$ \\
\hline \multirow{8}{*}{ Overall Mortality Rate } & Main model & $\begin{array}{l}15.95 * * * \\
(9.57,22.34)\end{array}$ & $\begin{array}{l}11.68^{* * *} \\
(7.08,16.28)\end{array}$ & $\begin{array}{l}2.56^{* * *} \\
(1.28,3.85)\end{array}$ & $\begin{array}{l}1.93^{* * *} \\
(1.07,2.79)\end{array}$ \\
\hline & First time test-takers & $\begin{array}{l}12.69 * * * \\
(7.72,17.65)\end{array}$ & $\begin{array}{l}8.92 * * * \\
(5.54,12.30)\end{array}$ & $\begin{array}{l}2.02 * * * \\
(1.03,3.02)\end{array}$ & $\begin{array}{l}1.48^{* * *} \\
(0.82,2.13)\end{array}$ \\
\hline & Explicitly NHW & $\begin{array}{l}14.38^{* * *} \\
(8.40,20.35)\end{array}$ & $\begin{array}{l}10.56^{* * *} \\
(6.27,14.85)\end{array}$ & $\begin{array}{l}2.23 * * * \\
(1.03,3.44)\end{array}$ & $\begin{array}{l}1.62 \text { *** } \\
(0.83,2.41)\end{array}$ \\
\hline & $>=20$ PI tests & $\begin{array}{l}33.94 * * * \\
(21.51,46.36)\end{array}$ & $\begin{array}{l}25.26^{* * *} \\
(15.80,34.71)\end{array}$ & $\begin{array}{l}5.06 * * * \\
(2.50,7.62)\end{array}$ & $\begin{array}{l}3.76^{* * *} \\
(2.01,5.51)\end{array}$ \\
\hline & $>=100$ PI tests & $\begin{array}{l}59.87^{* * *} \\
(39.39,80.35)\end{array}$ & $\begin{array}{l}47.23^{* * *} \\
(29.82,64.63)\end{array}$ & $\begin{array}{l}8.02 * * * \\
(3.76,12.28)\end{array}$ & $\begin{array}{l}5.93^{* * *} \\
(2.90,8.96)\end{array}$ \\
\hline & NYT data only & $\begin{array}{l}36.84^{* * *} \\
(20.86,52.82)\end{array}$ & $\begin{array}{l}27.05^{* * *} \\
(15.05,39.04)\end{array}$ & $\begin{array}{l}5.33^{* *} \\
(2.11,8.54)\end{array}$ & $\begin{array}{l}4.17^{* * *} \\
(2.01,6.33)\end{array}$ \\
\hline & Main model & $\begin{array}{l}215.52 * * * \\
(123.92,307.12)\end{array}$ & $\begin{array}{l}151.34^{* * *} \\
(83.37,219.31)\end{array}$ & $\begin{array}{l}44.16^{* *} \\
(24.95,63.38)\end{array}$ & $\begin{array}{l}34.95 * * * \\
(21.04,48.85)\end{array}$ \\
\hline & First time test-takers & $\begin{array}{l}169.32 * * * \\
(96.01,242.62)\end{array}$ & $\begin{array}{l}111.76^{* * *} \\
(59.18,164.35)\end{array}$ & $\begin{array}{l}34.09^{* * *} \\
(18.85,49.34)\end{array}$ & $\begin{array}{l}26.02 * * * \\
(14.95,37.09)\end{array}$ \\
\hline \multirow[t]{5}{*}{ Overall Incidence Rate } & Explicitly NHW & $\begin{array}{l}197.94^{* * *} \\
(112.45,283.44)\end{array}$ & $\begin{array}{l}140.70^{* * *} \\
(77.46,203.94)\end{array}$ & $\begin{array}{l}37.70 * * * \\
(19.86,55.54)\end{array}$ & $\begin{array}{l}28.61 * * * \\
(15.92,41.31)\end{array}$ \\
\hline & $>=20$ PI tests & $\begin{array}{l}464.22 * * * \\
(286.67,641.77)\end{array}$ & $\begin{array}{l}332.24 \text { *** } \\
(194.55,469.94)\end{array}$ & $\begin{array}{l}78.48^{* * *} \\
(41.08,115.87)\end{array}$ & $\begin{array}{l}58.35^{* * *} \\
(31.32,85.38)\end{array}$ \\
\hline & $>=100$ PI tests & $\begin{array}{l}820.77^{* * *} \\
(545.25 \\
1096.28)\end{array}$ & $\begin{array}{l}632.88^{* * *} \\
(404.57,861.19)\end{array}$ & $\begin{array}{l}114.86^{* * *} \\
(53.76,175.95)\end{array}$ & $\begin{array}{l}83.08^{* * *} \\
(37.94,128.22)\end{array}$ \\
\hline & NYT data only & $\begin{array}{l}554.86 * * * \\
(325.78,783.93)\end{array}$ & $\begin{array}{l}386.04^{* * *} \\
(229.00,543.09)\end{array}$ & $\begin{array}{l}93.58^{* * *} \\
(46.12,141.05)\end{array}$ & $\begin{array}{l}74.96^{* * *} \\
(46.76,103.16)\end{array}$ \\
\hline & Main model & $\begin{array}{l}91.78 * * \\
(35.97,147.58)\end{array}$ & $\begin{array}{l}106.82 \text { *** } \\
(47.79,165.85)\end{array}$ & $\begin{array}{l}20.13 * * \\
(7.33,32.93)\end{array}$ & $\begin{array}{l}19.71^{* * *} \\
(8.23,31.18)\end{array}$ \\
\hline \multirow[t]{6}{*}{ White Incidence Rate } & First time test-takers & $\begin{array}{l}74.95^{* *} \\
(30.07,119.84)\end{array}$ & $\begin{array}{l}86.11^{* * *} \\
(39.03,133.18)\end{array}$ & $\begin{array}{l}18.31^{* *} \\
(7.33,29.29)\end{array}$ & $\begin{array}{l}16.94^{* * *} \\
(7.49,26.40)\end{array}$ \\
\hline & Explicitly NHW & $\begin{array}{l}84.57^{* *} \\
(30.19,138.95)\end{array}$ & $\begin{array}{l}95.86^{* * *} \\
(39.61,152.12)\end{array}$ & $\begin{array}{l}17.43^{* *} \\
(5.16,29.70)\end{array}$ & $\begin{array}{l}16.93^{* *} \\
(5.90,27.96)\end{array}$ \\
\hline & $>=20$ PI tests & $\begin{array}{l}142.88^{* * *} \\
(67.12,218.65)\end{array}$ & $\begin{array}{l}169.82 * * * \\
(91.62,248.02)\end{array}$ & $\begin{array}{l}30.08 * * \\
(12.09,48.07)\end{array}$ & $\begin{array}{l}29.06^{* * *} \\
(13.21,44.92)\end{array}$ \\
\hline & $>=100$ PI tests & $\begin{array}{l}204.64^{* * *} \\
(92.49,316.79)\end{array}$ & $\begin{array}{l}249.98^{* * *} \\
(139.82,360.14)\end{array}$ & $\begin{array}{l}40.88^{* *} \\
(15.77,65.99)\end{array}$ & $\begin{array}{l}38.19^{* * *} \\
(16.46,59.91)\end{array}$ \\
\hline & Main model & $\begin{array}{l}224.04^{* * *} \\
(109.03,339.04)\end{array}$ & $\begin{array}{l}164.71^{* *} \\
(45.80,283.62)\end{array}$ & $\begin{array}{l}61.79^{* * *} \\
(39.81,83.77)\end{array}$ & $\begin{array}{l}48.54^{* * *} \\
(25.59,71.48)\end{array}$ \\
\hline & First time test-takers & $\begin{array}{l}168.33^{* * *} \\
(68.96,267.70)\end{array}$ & $\begin{array}{l}121.74 * \\
(20.03,223.44)\end{array}$ & $\begin{array}{l}50.83^{* * *} \\
(33.01,68.64)\end{array}$ & $\begin{array}{l}39.32^{* * *} \\
(20.96,57.69)\end{array}$ \\
\hline \multirow[t]{5}{*}{ Black Incidence Rate } & Explicitly NHW & $\begin{array}{l}196.46^{* * *} \\
(87.85,305.06)\end{array}$ & $\begin{array}{l}140.38^{*} \\
(27.79,252.97)\end{array}$ & $\begin{array}{l}56.79 * * * \\
(34.75,78.82)\end{array}$ & $\begin{array}{l}45.12^{* * *} \\
(22.30,67.94)\end{array}$ \\
\hline & $>=20$ PI tests & $\begin{array}{l}336.54^{* * *} \\
(186.21,486.86)\end{array}$ & $\begin{array}{l}257.76^{* *} \\
(97.89,417.63)\end{array}$ & $\begin{array}{l}81.19 * * * \\
(52.77,109.60)\end{array}$ & $\begin{array}{l}65.51^{* * *} \\
(35.77,95.25)\end{array}$ \\
\hline & $>=100 \mathrm{PI}$ tests & $\begin{array}{l}476.09 * * * \\
(260.10,692.08)\end{array}$ & $\begin{array}{l}410.74 * * * \\
(191.00,630.48)\end{array}$ & $\begin{array}{l}108.91^{* * *} \\
(68.56,149.26)\end{array}$ & $\begin{array}{l}89.05^{* * *} \\
(47.33,130.76)\end{array}$ \\
\hline & Main model & $\begin{array}{l}132.26 * * * \\
(56.88,207.64)\end{array}$ & $\begin{array}{l}57.89 \\
(-20.40,136.18)\end{array}$ & $\begin{array}{l}41.66^{* * *} \\
(25.55,57.78)\end{array}$ & $\begin{array}{l}28.83^{* * *} \\
(12.63,45.03)\end{array}$ \\
\hline & First time test-takers & $\begin{array}{l}93.38^{* *} \\
(23.70,163.05)\end{array}$ & $\begin{array}{l}35.63 \\
(-36.55,107.81)\end{array}$ & $\begin{array}{l}32.51 * * * \\
(20.08,44.95)\end{array}$ & $\begin{array}{l}22.38^{* * *} \\
(9.83,34.93)\end{array}$ \\
\hline \multirow[t]{3}{*}{$\begin{array}{l}\text { Black-White Incidence } \\
\text { Rate Gap }\end{array}$} & Explicitly NHW & $\begin{array}{l}111.88 * * \\
(41.26,182.51)\end{array}$ & $\begin{array}{l}44.52 \\
(-28.82,117.85)\end{array}$ & $\begin{array}{l}39.36^{* * *} \\
(23.09,55.63)\end{array}$ & $\begin{array}{l}28.19 * * * \\
(11.90,44.49)\end{array}$ \\
\hline & $>=20$ PI tests & $\begin{array}{l}193.65^{* * *} \\
(96.59,290.71)\end{array}$ & $\begin{array}{l}87.94 \\
(-19.01,194.89)\end{array}$ & $\begin{array}{l}51.11^{* * *} \\
(30.57,71.65)\end{array}$ & $\begin{array}{l}36.45^{* * *} \\
(15.62,57.27)\end{array}$ \\
\hline & $>=100 \mathrm{PI}$ tests & $\begin{array}{l}271.45 * * * \\
(135.03,407.87)\end{array}$ & $\begin{array}{l}160.76^{*} \\
(14.91,306.60)\end{array}$ & $\begin{array}{l}68.03^{* * *} \\
(38.21,97.85)\end{array}$ & $\begin{array}{l}50.86^{* * *} \\
(21.06,80.66)\end{array}$ \\
\hline
\end{tabular}

NHW = non-Hispanic White; NYT = The New York Times. Estimates correspond to rate differences (and 95\% confidence intervals). All outcomes are calculated per 10,000 individuals. ${ }^{*} p<0.05,{ }^{* *} p<0.01,{ }^{* * *} p<0.001$ 
Appendix E.2. First-Time IAT Test-Takers

Project Implicit respondents report the number of times they have previously taken the IAT. For our primary analysis, we retained all racial bias tests, regardless of whether the respondent had previously taken a test. This decision was motivated by our goal of capturing the current social context in each county over a specified time period (2017-2019). Therefore, if a respondent took the IAT in 2009 and again in 2018, we would want to include their score in our measure of 2017-2019 county-level racial bias. Similarly, we would want to retain a respondent's racial bias data even if they previously took the IAT in a different county. Because the dataset does not indicate when or where a previous test was taken, we could not selectively include or exclude previous tests. However, as a sensitivity analysis, we excluded those who had taken the test previously $(n=245,101)$ or who did not report on number of previous tests $(n=758)$, restricting the sample to first-time IAT respondents (66.6\%) [40]. Basic demographics and racial bias scores between first-time and repeat test-takers were very similar, with slightly higher racial bias scores among first-time test-takers compared to those who have previously taken the IAT.

Table A7. Characteristics of IAT test-takers by previous tests, 2017-2019.

\begin{tabular}{|c|c|c|}
\hline Characteristic & $\begin{array}{c}\text { Primary Sample: All } \\
\text { Respondents }(\mathrm{n}=723,271)\end{array}$ & $\begin{array}{l}\text { Sensitivity Sample: First Time } \\
\text { Respondents }(\mathrm{n}=477,404)\end{array}$ \\
\hline Gender identity & $\mathrm{n}(\%)$ & $\mathrm{n}(\%)$ \\
\hline Woman & $451,908(62.5)$ & $286,744(60.1)$ \\
\hline Man & $262,992(36.4)$ & $185,994(39.0)$ \\
\hline Nonbinary & $7939(1.1)$ & $4395(0.9)$ \\
\hline NA & $417(0.1)$ & $271(0.1)$ \\
\hline Age (mean (SD)) & $29.7(13.9)$ & $29.4(14.1)$ \\
\hline \multicolumn{3}{|l|}{ Educational attainment } \\
\hline$<$ high school & $97,418(13.5)$ & $75,499(15.8)$ \\
\hline high school graduate & $283,493(39.2)$ & $190,310(39.9)$ \\
\hline bachelor's degree & $340,940(47.1)$ & $210,677(44.1)$ \\
\hline Missing & $1405(0.2)$ & $918(0.2)$ \\
\hline \multicolumn{3}{|l|}{ Number previous tests } \\
\hline (- & $477,404(66.0)$ & $477,404(100)$ \\
\hline 1 & $143,625(19.9)$ & 0 \\
\hline 2 & $52,608(7.3)$ & 0 \\
\hline $3-5$ & $39,000(5.4)$ & 0 \\
\hline $6+$ & $9861(1.4)$ & 0 \\
\hline Missing & $758(0.1)$ & 0 \\
\hline Implicit racial bias (mean (SD)) & $0.36(0.41)$ & $0.39(0.40)$ \\
\hline Explicit racial bias (mean (SD)) & $0.24(1.54)$ & $0.29(1.55)$ \\
\hline
\end{tabular}

Primary sample: restricted to NHW, US-based respondents with complete and adequate test data and county data. Sensitivity sample: restricted to NHW, US-based respondents with complete and adequate test data, complete county data, and taking the IAT for the first time (excludes those with num_tests $>0$ OR num_tests $=$ NA).

\section{Appendix E.3. Construction of Non-Hispanic White}

Our analysis is focused on the racial bias of non-Hispanic White Project Implicit respondents. Therefore, we included all White respondents identifying as "not Hispanic or Latino" and excluded those identifying as White and "Hispanic or Latino." However, a small proportion of White respondents indicated "unknown" ethnicity or did not report an ethnic identity. These respondents were retained in the final sample under the assumption that non-Hispanic/Latino individuals would be more likely to report ethnicity = "unknown" or leave the question blank than those identifying as Hispanic/Latino. Thus, the sample was restricted to respondents who identified as White and who did not explicitly indicate ethnicity is "Hispanic/Latino." Those identifying as White for whom ethnicity was missing or unknown ( $\mathrm{n}=65,533)$ were assigned non-Hispanic White and retained in the county-averages $(\mathrm{n}=723,271)$. As a sensitivity analysis, we excluded White respondents with unknown or missing 
ethnicity, retaining only those who explicitly reported ethnicity $=$ "Not Hispanic or Latino" ( $n=657,738)$. Basic demographics and racial bias scores between non-Hispanic White respondents under the two coding approaches were nearly identical.

Table A8. Characteristics of IAT test-takers by construction of non-Hispanic White, 2017-2019.

\begin{tabular}{|c|c|c|}
\hline Characteristic & Primary Coding $(n=723,256)$ & Sensitivity Coding $(n=657,727)$ \\
\hline Gender identity & $\mathrm{n}(\%)$ & $\mathrm{n}(\%)$ \\
\hline Woman & $451,908(62.5)$ & $414,745(63.1)$ \\
\hline Man & $262,992(36.4)$ & $235,520(35.8)$ \\
\hline Nonbinary & $7939(1.1)$ & $7106(1.1)$ \\
\hline $\mathrm{NA}$ & $417(0.1)$ & $367(0.1)$ \\
\hline Age (mean (SD)) & $29.7(13.9)$ & $29.9(13.8)$ \\
\hline \multicolumn{3}{|l|}{ Educational attainment } \\
\hline$<$ high school & $97,418(13.5)$ & $80,968(12.3)$ \\
\hline high school graduate & $283,493(39.2)$ & $255,932(38.9)$ \\
\hline bachelor's degree & $340,940(47.1)$ & $319,718(48.6)$ \\
\hline Missing & $1405(0.2)$ & $1120(0.2)$ \\
\hline \multicolumn{3}{|l|}{ Number previous tests } \\
\hline 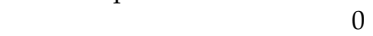 & $477,404(66.0)$ & $429,692(65.3)$ \\
\hline 1 & $143,625(19.9)$ & $132,160(20.1)$ \\
\hline 2 & $52,608(7.3)$ & $49,065(7.5)$ \\
\hline $3-5$ & $39,000(5.4)$ & $36,838(5.6)$ \\
\hline $6+$ & $9861(1.4)$ & $9397(1.4)$ \\
\hline Missing & $758(0.1)$ & $586(0.1)$ \\
\hline Implicit racial bias (mean (SD)) & $0.36(0.41)$ & $0.36(0.42)$ \\
\hline Explicit racial bias (mean (SD)) & $0.24(1.54)$ & $0.25(1.53)$ \\
\hline
\end{tabular}

Project Implicit sample restricted to NHW, US-based respondents with complete and adequate test data and county data. Primary coding: Restricted to respondents who identified as White and who did not indicate ethnicity is "Hispanic/Latino." Includes those identifying as White for whom ethnicity was missing or unknown ( $n=65,533)$, Sensitivity coding: Restricted to respondents who identified as White and explicitly stated ethnicity = not Hispanic. Excludes those identifying as White for whom ethnicity was missing or unknown $(n=65,533)$.

\section{References}

1. Chen, J.T.; Krieger, N. Revealing the Unequal Burden of COVID-19 by Income, Race/Ethnicity, and Household Crowding. J. Public Heal. Manag. Pr. 2020. [CrossRef]

2. Oppel, R.A.; Gebelhoff, R.; Lai, K.K.R.; Wright, W.; Smith, M. The Fullest Look Yet at the Racial Inequity of Coronavirus. The New York Times, 5 July 2020.

3. The Covid Tracking Project. Racial Data Dashboard. 2020. Available online: https://covidtracking.com/race/ dashboard (accessed on 25 May 2020).

4. Johns Hopkins Coronavirus Resource Center. Global Map. Available online: https://coronavirus.jhu.edu/ map.html (accessed on 6 October 2020).

5. Chen, J.T.; Waterman, P.D.; Krieger, N.; Krieger, N. COVID-19 and the unequal surge in mortality rates in Massachusetts, by city/town and ZIP Code measures of poverty, household crowding, race/ethnicity, and racialized economic segregation. In Harvard Center for Populatin and Development Studies: Working Paper Series; Harvard School of Public Health: Boston, MA, USA, 2020; p. 19.

6. Holmes, L.; Enwere, M.; Williams, J.; Ogundele, B.; Chavan, P.; Piccoli, T.; Chinaka, C.; Comeaux, C.; Pelaez, L.; Okundaye, O.; et al. Black-White Risk Differentials in COVID-19 (SARS-COV2) Transmission, Mortality and Case Fatality in the United States: Translational Epidemiologic Perspective and Challenges. Int. J. Environ. Res. Public Heal. 2020, 17, 4322. [CrossRef]

7. Egede, L.E.; Walker, R.J. Structural Racism, Social Risk Factors, and Covid-19-A Dangerous Convergence for Black Americans. N. Engl. J. Med. 2020, 383, e77. [CrossRef] [PubMed]

8. Berkowitz, R.L.; Gao, X.; Michaels, E.; Mujahid, M.S. Structurally vulnerable neighbourhood environments and racial/ethnic COVID-19 inequities. Cities Heal. 2020, 1-4. [CrossRef]

9. Phelan, J.C.; Link, B.G. Is Racism a Fundamental Cause of Inequalities in Health? Annu. Rev. Sociol. 2015, 41, 311-330. [CrossRef]

10. Powell, J.A. Structural racism: Building upon the insights of John Calmore. NCL Rev. 2007, 86, 791. 
11. Bailey, Z.D.; Krieger, N.; Agénor, M.; Graves, J.; Linos, N.; Bassett, M.T. Structural racism and health inequities in the USA: Evidence and interventions. Lancet 2017, 389, 1453-1463. [CrossRef]

12. Gee, G.C.; Ford, C.L. Structural racism and health inequities. Du Bois Rev. Soc. Sci. Res. Race 2011, 8, 115-132. [CrossRef]

13. Harrell, C.J.P.; Burford, T.I.; Cage, B.N.; Nelson, T.M.; Shearon, S.; Thompson, A.; Green, S. Multiple pathways linking racism to health outcomes. Du Bois Rev. Soc. Sci. Res. Race 2011, 8, 143-157. [CrossRef]

14. Barnett, M.L.; Grabowski, D.C. Nursing homes are ground zero for COVID-19 pandemic. JAMA Health Forum Am. Med Assoc. 2020, e200369. [CrossRef]

15. Hawks, L.; Woolhandler, S.; McCormick, D. COVID-19 in Prisons and Jails in the United States. JAMA Intern. Med. 2020, 180, 1041. [CrossRef]

16. Abedi, V.; Olulana, O.; Avula, V.; Chaudhary, D.; Khan, A.; Shahjouei, S.; Li, J.; Zand, R. Racial, Economic, and Health Inequality and COVID-19 Infection in the United States. J. Racial Ethn. Heal. Disparities 2020, 1-11. [CrossRef]

17. Wadhera, R.K.; Wadhera, P.; Gaba, P.; Figueroa, J.F.; Maddox, K.E.J.; Yeh, R.W.; Shen, C. Variation in COVID-19 Hospitalizations and Deaths Across New York City Boroughs. JAMA 2020, 323, 2192-2195. [CrossRef] [PubMed]

18. Raifman, M.A.; Raifman, J.R. Disparities in the Population at Risk of Severe Illness from COVID-19 by Race/Ethnicity and Income. Am. J. Prev. Med. 2020, 59, 137-139. [CrossRef] [PubMed]

19. Payne, B.K.; Vuletich, H.A.; Lundberg, K.B. The Bias of Crowds: How Implicit Bias Bridges Personal and Systemic Prejudice. Psychol. Inq. 2017, 28, 233-248. [CrossRef]

20. Williams, D.R.; Lawrence, J.A.; Davis, B.A. Racism and Health: Evidence and Needed Research. Annu. Rev. Public Heal. 2019, 40, 105-125. [CrossRef]

21. Jost, J.T.; Rudman, L.A.; Blair, I.V.; Carney, D.R.; Dasgupta, N.; Glaser, J.; Hardin, C.D. WITHDRAWN: The existence of implicit bias is beyond reasonable doubt: A refutation of ideological and methodological objections and executive summary of ten studies that no manager should ignore. Res. Organ. Behav. 2009. [CrossRef]

22. Hehman, E.; Calanchini, J.; Flake, J.K.; Leitner, J.B. Establishing construct validity evidence for regional measures of explicit and implicit racial bias. J. Exp. Psychol. Gen. 2019, 148, 1022-1040. [CrossRef]

23. Blair, I.V.; Brondolo, E. Moving beyond the individual: Community-level prejudice and health. Soc. Sci. Med. 2017, 183, 169-172. [CrossRef]

24. Leitner, J.B.; Hehman, E.; Snowden, L.R. States higher in racial bias spend less on disabled medicaid enrollees. Soc. Sci. Med. 2018, 208, 150-157. [CrossRef] [PubMed]

25. Orchard, J.; Price, J. County-level racial prejudice and the black-white gap in infant health outcomes. Soc. Sci. Med. 2017, 181, 191-198. [CrossRef] [PubMed]

26. Hehman, E.; Flake, J.K.; Calanchini, J. Disproportionate Use of Lethal Force in Policing Is Associated With Regional Racial Biases of Residents. Soc. Psychol. Pers. Sci. 2018, 9, 393-401. [CrossRef]

27. Huang, D.; Huang, Y.; Adams, N.; Nguyen, T.T.; Nguyen, Q.C. Twitter-Characterized Sentiment Towards Racial/Ethnic Minorities and Cardiovascular Disease (CVD) Outcomes. J. Racial Ethn. Heal. Disparities 2020, 7, 888-900. [CrossRef] [PubMed]

28. Lee, Y.; Muennig, P.; Kawachi, I.; Hatzenbuehler, M.L. Effects of Racial Prejudice on the Health of Communities: A Multilevel Survival Analysis. Am. J. Public Heal. 2015, 105, 2349-2355. [CrossRef] [PubMed]

29. Leitner, J.B.; Hehman, E.; Ayduk, O.; Mendoza-Denton, R. Blacks' Death Rate Due to Circulatory Diseases Is Positively Related to Whites' Explicit Racial Bias. Psychol. Sci. 2016, 27, 1299-1311. [CrossRef]

30. Leitner, J.B.; Hehman, E.; Ayduk, O.; Mendoza-Denton, R. Racial bias is associated with ingroup death rate for Blacks and Whites: Insights from Project Implicit. Soc. Sci. Med. 2016, 170, 220-227. [CrossRef]

31. Project Implicit. 2010. Available online: http://projectimplicit.net/index.html (accessed on 21 January 2018).

32. Montanaro, D. Majority of Americans Say Trump Increased Racial Tensions after George Floyd's Death, Poll Finds. Weekend Edition Saturday, Ed. Hosted by Scott Simon. National Public Radio. 6 June 2020. Transcript. Available online: https://www.npr.org/2020/06/06/871404645/majority-of-americans-say-trumpincreased-racial-tensions-after-george-floyds-de (accessed on 10 September 2020).

33. .Greenwald, A.G.; Nosek, B.A.; Banaji, M.R. Understanding and using the implicit association test: I. An improved scoring algorithm. J. Personal. Soc. Psychol. 2003, 85, 197. [CrossRef] 
34. Painter, M.; Qiu, T. Political Beliefs affect Compliance with COVID-19 Social Distancing Orders. SSRN Electron. J. 2020. [CrossRef]

35. US Census Bureau. 2014-2018 American Community Survey 5-Year Estimates. Available online: https: //data.census.gov/cedsci/ (accessed on 12 June 2020).

36. Glenn, E.H.; Glenn, M.E.H. 'acs'. Download, Manipulate, and Present American Community Survey and Decennial Data from the US Census. R Package Version 2.1.4. Available online: https://cran.r-project.org/ web/packages/acs/acs.pdf (accessed on 12 June 2020).

37. McGovern, A.; Morris WMcGovern, A.; Morris, W. 2016 Presidential Election Results [Data Set and Code Book]. 2016. Available online: https://zenodo.org/record/3975765\#.X7t2U837RPY (accessed on 23 November 2020).

38. ArcGIS. Persons per Square Mile by County. Available online: http://hub.arcgis.com/datasets/ fab7849b55d54f0f8f246605f6ee9306/geoservice?geometry=-302.697\%2C-0.072\%2C57.303\%2C76.663\& layer $=12$ (accessed on 26 July 2020).

39. Greenland, S. Chapter 21: Introduction to regression modeling. Mod. Epidemiol. 1998, 2, 401-434.

40. Charlesworth, T.E.S.; Banaji, M.R. Patterns of Implicit and Explicit Attitudes: I. Long-Term Change and Stability from 2007 to 2016. Psychol. Sci. 2019, 30, 174-192. [CrossRef] [PubMed]

41. Nguyen, T.T.; Meng, H.-W.; Sandeep, S.; McCullough, M.; Yu, W.; Lau, Y.; Huang, D.; Nguyen, Q.C. Twitter-derived measures of sentiment towards minorities (2015-2016) and associations with low birth weight and preterm birth in the United States. Comput. Hum. Behav. 2018, 89, 308-315. [CrossRef] [PubMed]

42. Connor, P.; Sarafidis, V.; Zyphur, M.J.; Keltner, D.; Chen, S. Income Inequality and White-on-Black Racial Bias in the United States: Evidence From Project Implicit and Google Trends. Psychol. Sci. 2019, 30, $205-222$. [CrossRef] [PubMed]

43. Metropolitan Transit Authority. MTA-Wide Workforce. 2019. Available online: https://www.documentcloud. org/documents/6827449-Screen-Shot-2020.html (accessed on 1 June 2020).

44. US Department of Labor Bureau of Labor Statistics. Labor Force Characteristics by Race and Ethnicity. 2018. Available online: https://www.bls.gov/opub/reports/race-and-ethnicity/2018/home.htm (accessed on 1 June 2020).

45. Jones, A. Segregation and cardiovascular illness: The role of individual and metropolitan socioeconomic status. Heal. Place 2013, 22, 56-67. [CrossRef] [PubMed]

46. Huang, C.; Wang, Y.; Li, X.; Ren, L.; Zhao, J.; Hu, Y.; Zhang, L.; Fan, G.; Xu, J.; Gu, X. Clinical features of patients infected with 2019 novel coronavirus in Wuhan, China. Lancet 2020, 395, 497-506. [CrossRef]

47. Kawachi, I.; Berkman, L.F. Social Capital, Social Cohesion, and Health. Soc. Epidemiol. 2014, 2, $290-319$. [CrossRef]

48. Bai, J.; Jin, W.; Wan, C. The Impact of Social Capital on Individual Responses to COVID-19 Pandemic: Evidence from Social Distancing. SSRN Electron. J. 2020. [CrossRef]

49. MacIntyre, S.; Maciver, S.; Sooman, A. Area, Class and Health: Should we be Focusing on Places or People? J. Soc. Policy 1993, 22, 213-234. [CrossRef]

50. Sampson, R.J.; Raudenbush, S.W.; Earls, F. Neighborhoods and Violent Crime: A Multilevel Study of Collective Efficacy. Sci. 1997, 277, 918-924. [CrossRef]

51. Pettigrew, T.F.; Tropp, L.R.; Wagner, U.; Christ, O. Recent advances in intergroup contact theory. Int. J. Intercult. Relations 2011, 35, 271-280. [CrossRef]

52. Finlay, K.A.; Stephan, W.G. Improving Intergroup Relations: The Effects of Empathy on Racial Attitudes1. J. Appl. Soc. Psychol. 2000, 30, 1720-1737. [CrossRef]

53. Stephan, W.G.; Finlay, K. The Role of Empathy in Improving Intergroup Relations. J. Soc. Issues 1999, 55, 729-743. [CrossRef]

54. Harrell, S.P. A multidimensional conceptualization of racism-related stress: Implications for the well-being of people of color. Am. J. Orthopsychiatry 2000, 70, 42-57. [CrossRef] [PubMed]

55. Goosby, B.J.; Cheadle, J.E.; Mitchell, C. Stress-Related Biosocial Mechanisms of Discrimination and African American Health Inequities. Annu. Rev. Sociol. 2018, 44, 319-340. [CrossRef]

56. Bae, Y.-S.; Shin, E.-C.; Bae, Y.-S.; Van Eden, W. Stress and immunity. Front. Immunol. 2019, 10, 245. [CrossRef]

57. Cassel, J. The contribution of the social environment to host resistance: The Fourth Wade Hampton Frost Lecture. Am. J. Epidemiol. 1976, 104, 107-123. [CrossRef] 
58. Frey, W.H. A Roaring Sun Belt Surge Has Inverted the Demographics and Politics of COVID-19. Brookings. Available online: https://www.brookings.edu/blog/the-avenue/2020/06/19/covid-19s-sun-belt-surge-hasrecast-the-pandemics-impact/ (accessed on 3 November 2020).

59. Krieger, N.; Waterman, P.D.; Spasojevic, J.; Li, W.; Maduro, G.; Van Wye, G. Public Health Monitoring of Privilege and Deprivation With the Index of Concentration at the Extremes. Am. J. Public Heal. 2016, 106, 256-263. [CrossRef]

Publisher's Note: MDPI stays neutral with regard to jurisdictional claims in published maps and institutional affiliations.

(C) 2020 by the authors. Licensee MDPI, Basel, Switzerland. This article is an open access article distributed under the terms and conditions of the Creative Commons Attribution (CC BY) license (http://creativecommons.org/licenses/by/4.0/). 